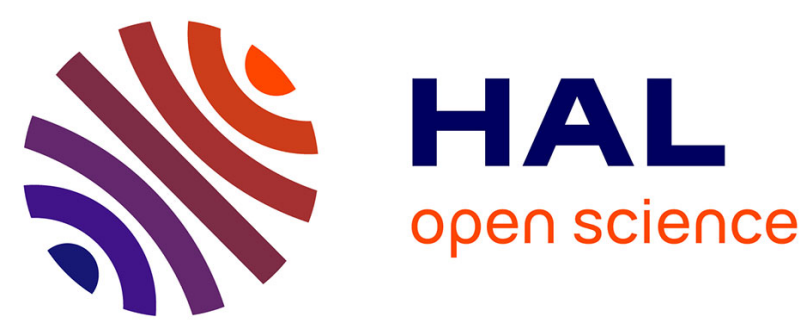

\title{
Orthohalogen substituents dramatically enhance hydrogen bonding of aromatic ureas in solution
}

Ilaria Giannicchi, Benjamin Jouvelet, Benjamin Isare, Mathieu Linares, Antonella Dalla Cort, Laurent Bouteiller

\section{- To cite this version:}

Ilaria Giannicchi, Benjamin Jouvelet, Benjamin Isare, Mathieu Linares, Antonella Dalla Cort, et al.. Orthohalogen substituents dramatically enhance hydrogen bonding of aromatic ureas in solution. Chemical Communications, 2014, 50, pp.611-613. 10.1039/C3CC47447J . hal-01122545

\section{HAL Id: hal-01122545 \\ https://hal.sorbonne-universite.fr/hal-01122545}

Submitted on 4 Mar 2015

HAL is a multi-disciplinary open access archive for the deposit and dissemination of scientific research documents, whether they are published or not. The documents may come from teaching and research institutions in France or abroad, or from public or private research centers.
L'archive ouverte pluridisciplinaire HAL, est destinée au dépôt et à la diffusion de documents scientifiques de niveau recherche, publiés ou non, émanant des établissements d'enseignement et de recherche français ou étrangers, des laboratoires publics ou privés. 
Chem. Commun. 2014, 50, 611

\title{
Orthohalogen substituents dramatically enhance hydrogen bonding of aromatic ureas in solution
}

\author{
Ilaria Giannicchi, ${ }^{\mathrm{c}}$ Benjamin Jouvelet, ${ }^{\text {ab }}$ Benjamin Isare, ${ }^{\text {ab }}$ Mathieu Linares, ${ }^{\mathrm{d}}$ Antonella Dalla Cort ${ }^{\mathrm{c}}$ and \\ Laurent Bouteiller*a,b
}

The phenylurea moiety is a ubiquitous synthon in supramolecular chemistry. Here we report that the introduction of chlorine or bromine atoms in the ortho positions to the urea unit is a simple and very efficient way to improve its intermolecular hydrogen bond (HB) donor character. This effect was demonstrated in solution both in the context of bis-ureas self-association and of mono-ureas hydrogen bonding to strong $\mathrm{HB}$ acceptors.

Developing supramolecular synthons with an improved efficiency and selectivity is an important endeavour in the context of the current increasing complexity of self-assembled systems. ${ }^{1}$ A well-known strategy to enhance the HB donor ability of receptors is to introduce electron withdrawing substituents, but a careful design is required to avoid establishing competing intramolecular interactions. Here, we focused our attention on the phenylurea moiety, that is an ubiquitous synthon in supramolecular chemistry. Its direct synthetic accessibility and its HB donor ability have been exploited in the fields of anion complexation, ${ }^{2}$ organocatalysis $^{3}$ and foldamer conformational control. ${ }^{4}$ Moreover, the self-complementarity of the phenylurea synthon is a reliable design motif for crystal engineering, ${ }^{5}$ organogelators, ${ }^{6}$ liquid crystals, ${ }^{7}$ supramolecular polymers, ${ }^{8}$ nanostructured polymers, ${ }^{9}$ self-assembled capsules ${ }^{10}$ and monolayers. ${ }^{11}$ The effect of various electron withdrawing substituents on urea assembly is well-known, ${ }^{12}$ but the case of halogen atoms in ortho position of the phenylurea moiety has rarely been investigated, probably because such substitution was shown to favour intramolecular HBs. The intramolecular HB to an ortho chlorine atom totally suppresses intermolecular HB for a trisubstituted urea. ${ }^{13}$ However, in the case of fluorine, an interesting conformational effect has been described: the presence of a single fluorine atom in ortho position enforces a coplanar conformation of the aromatic and urea moieties, whereas the presence of two fluorine atoms in 2,6 positions is responsible for the clear loss of coplanarity. This is attributed to the electrostatic repulsion between the oxygen and both fluorine atoms, which therefore forbids the formation of a weak N-H ${ }^{\cdots} \mathrm{F}$ intramolecular HB. ${ }^{14}$ Although the strength of intermolecular HB cannot be deduced from the crystalline structures reported, it is noteworthy that the bisfluorinated urea forms the usual bifurcated intermolecular $\mathrm{HB}$, whereas the monofluorinated analogue does not. This conformational effect is particularly relevant in the context of self-association, because the phenylurea moiety usually displays a strong conformational change on self-assembly to avoid steric clash between the aromatic groups and to allow some $\pi$-stacking interaction. ${ }^{15,16}$ We therefore reasoned that the presence of two halogen atoms in ortho position to the urea group could have a favourable influence on intermolecular hydrogen bonding, due to a better conformational preorganization of the monomer. In this communication, we report that indeed the presence of halogen atoms in the ortho positions to the urea considerably improves intermolecular hydrogen bonding and that, surprisingly, in the case of chlorine and bromine, this effect is accompanied by the formation of an intramolecular HB.

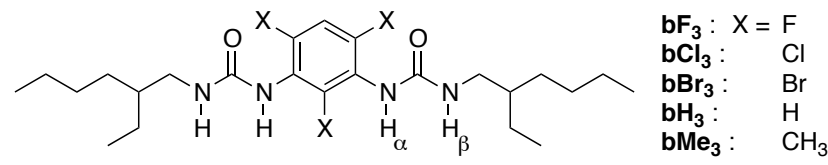

Scheme 1

We consider the 2,4,6-trihalogenated bis-ureas represented in Scheme 1 together with the unsubstituted and trimethylated bis-ureas as references. At low concentration $\left(2 \times 10^{-5} \mathrm{~mol} / \mathrm{L}\right)$ in chloroform, FTIR spectra show that all these compounds are monomeric and that an intramolecular interaction between the $\mathrm{N}-\mathrm{H}_{\alpha}$ (Scheme 1) and the halogens in ortho position is present in the case of the chlorinated $\mathbf{b C l}_{\mathbf{3}}$ and brominated $\mathbf{b B r}_{3}$ bis-ureas (see ESI†). Ab initio calculations on model mono-ureas support these results and highlight the significant influence of the substituents on the dihedral angle $(\varphi)$ between the urea and aromatic groups (see ESI $\dagger$ ). In the absence of substituent $\left(\mathbf{b H}_{\mathbf{3}}\right)$ the most stable conformation is coplanar $(\varphi$ $=0)$. With fluorine $\left(\mathbf{b F}_{\mathbf{3}}\right)$ or methyl $\left(\mathbf{b} \mathbf{M e} \mathbf{e}_{3}\right)$ substituents, the most stable conformations correspond to a dihedral angle of 60 and $120^{\circ}$, separated by a small barrier $(1 \mathrm{kcal} / \mathrm{mol})$ at $\varphi=$ $90^{\circ}$. With chlorine $\left(\mathbf{b C l}_{3}\right)$ or bromine $\left(\mathbf{b B r}_{3}\right)$ substituents, the energy surface is completely flat from $\varphi=60$ to $120^{\circ}$.

At higher concentration $\left(10^{-2} \mathrm{~mol} / \mathrm{L}\right)$, FTIR shows that intermolecular HBs are formed (Fig. 1). In fact, at this concentration, the free N-H vibration band $\left(3420-3450 \mathrm{~cm}^{-1}\right)^{8}$ is small in the case of $\mathbf{b H}_{3}$ and $\mathbf{b} \mathbf{M e}_{3}$ and is barely detectable in the case of $\mathbf{b F}_{3}, \mathbf{b C l}_{\mathbf{3}}$ and $\mathbf{b B r} \mathbf{r}_{3}$, which qualitatively hints at the positive effect of the halogens on the strength of intermolecular association. The structure of the assemblies was examined by Small Angle Neutron Scattering (SANS). All compounds yield very similar scattering profiles in 
deuterated chloroform (Fig. 2): the low angle region shows a $\mathrm{q}^{-1}$ dependence over more than a decade, which is characteristic for long and rigid fibrillar objects. In principle, the specific dimensions of the scattering objects can be deduced from a fit to a form factor calculated according to a suitable geometrical model. In the present case the use of a form factor for infinitely long rigid filaments (with a circular cross-section and a uniform scattering length density profile) ${ }^{17}$ yields an excellent fit over the whole q range (Fig. 2). The values deduced from the fits are summarized in Table S3. According to these results, all five bis-ureas form very similar assemblies, $\$$ with a relatively low linear density $\left(\mathrm{n}_{\mathrm{L}} \approx 0.25 \AA^{-}\right.$ ${ }^{1}$ ), which corresponds to the presence of a single bis-urea in the cross-section. ${ }^{17}$

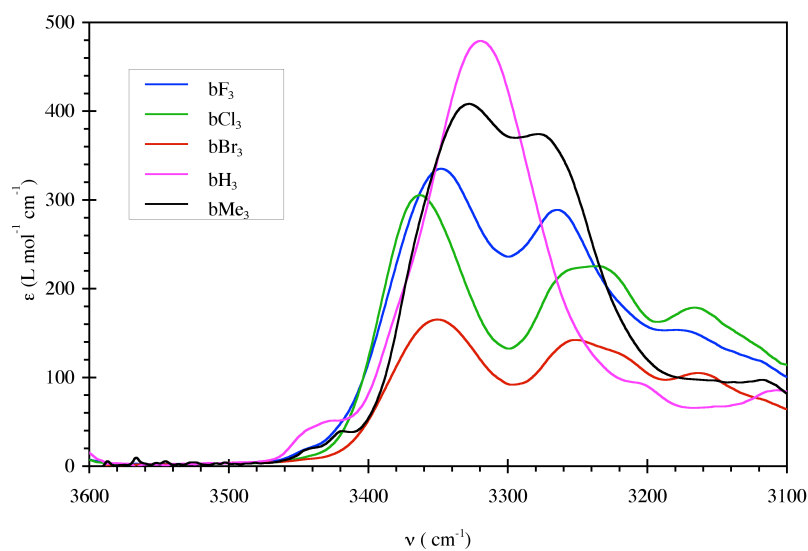

Fig. 1 FTIR spectra for bis-ureas at $10^{-2} \mathrm{~mol} / \mathrm{L}$ in chloroform $\left(20^{\circ} \mathrm{C}\right)$.

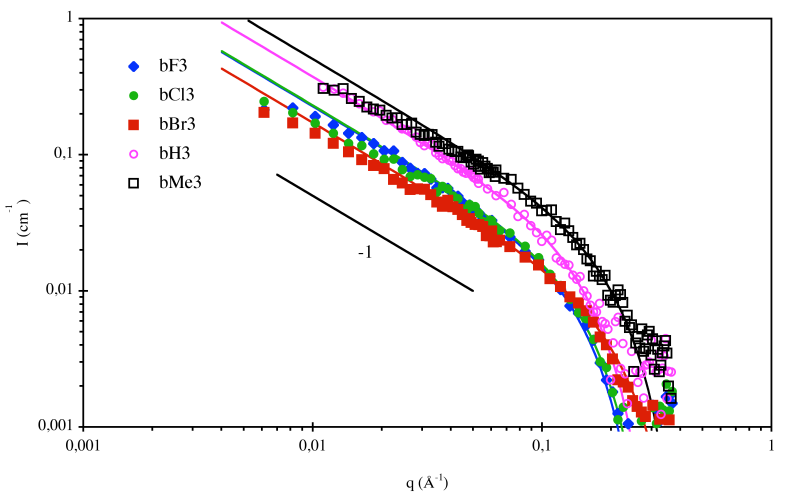

Fig. 2 SANS intensity (I) versus scattering vector (q) for bis-urea solutions in $\mathrm{CDCl}_{3}$ at $15 \mathrm{~g} / \mathrm{L}$ (ca $0.03 \mathrm{~mol} / \mathrm{L}$ ) and $22^{\circ} \mathrm{C}$. The plain curves are fits according to a model for long rigid filaments with a circular crosssection (characteristic dimensions in Table S3).

The fact that all five bis-ureas self-assemble into long filaments with the same structure makes the comparison of their association strength particularly relevant. Therefore, their stability to dilution was probed by Isothermal Titration Calorimetry (ITC). Fig. S5 shows the heat effect produced when a drop of a solution containing a self-assembled bis-urea is diluted into chloroform. The endothermic signal results from the breaking of hydrogen bonds consequent to the dilution. Qualitatively, it is possible to see that the halogenated bis-ureas are more strongly self-associated than $\mathbf{b H}_{3}$ and $\mathbf{b M e}_{3}$ because in their case the concentration of the experiment had to be reduced to induce full dissociation. To quantify this effect, the experiments were reproduced with optimized initial concentrations and injection volumes, and the heat signal was integrated and plotted versus the concentration in the calorimetric cell (Fig. 3). From these curves, it is possible to determine graphically the critical concentration $\left(\mathrm{c}^{*}\right)^{18}$ below which the assemblies dissociate into monomers: the stability of the assemblies increases very strongly from the reference bis-ureas $\mathbf{b H}_{3}\left(\mathrm{c}^{*}=1.6 \mathrm{mM}\right)$ and $\mathbf{b M e}_{3}\left(\mathrm{c}^{*}=0.6 \mathrm{mM}\right)$ to the halogenated bis-ureas $\mathbf{b F}_{3}\left(\mathrm{c}^{*}=\right.$ $0.1 \mathrm{mM}), \mathbf{b B r}_{3}\left(\mathrm{c}^{*}=0.056 \mathrm{mM}\right)$ and $\mathbf{b C l}_{3}\left(\mathrm{c}^{*}=0.041 \mathrm{mM}\right)$. Moreover, the exact shape of the titration curves can be accounted for by a simple mass action law model describing the evolution of the concentration of monomers (M) and filaments $\left(\mathrm{F}_{\mathrm{n}}\right)$ of any degree of polymerisation (n). ${ }^{19}$ The values deduced from the fit for the association constants and the enthalpy of association are reported in Table S4.

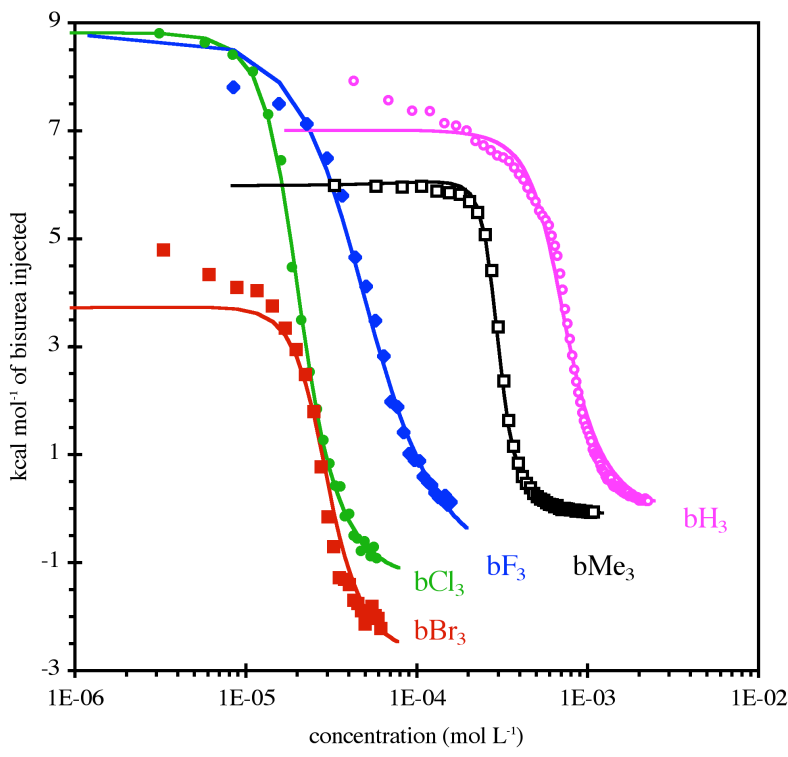

Fig. 3 ITC enthalpograms for bis-urea solutions in chloroform injected into chloroform versus total bis-urea concentration in the cell $\left(\mathrm{T}=20^{\circ} \mathrm{C}\right)$.

These results show that the replacement in the ortho positions of methyl groups with chlorine or bromine atoms stabilizes the assemblies by more than one order of magnitude. This huge effect may potentially be due to several factors:

- the electron withdrawing effect of the halogen atom which should enhance the HB donor character of $\mathrm{N}-\mathrm{H}_{\alpha}$, as confirmed by ab initio calculations on model mono-ureas (see ESI $\dagger$ );

- the polarization of the aromatic ring by the halogen atom which could increase $\pi$-stacking interactions;

- the repulsion between oxygen and halogen atoms which may induce a conformational effect.

The fact that the stability of the assemblies does not reflect the electronegativity scale among the halogen atoms means that at least a couple of different effects are involved.

To probe the generality of this halogen effect, we synthesized structurally simpler mono-ureas (Fig. 4) and 
probed their association with strong hydrogen bond acceptors such as dimethylsulfoxide (DMSO) and triphenylphosphine oxide (TPPO). Sufficiently dilute solutions of the mono-ureas were prepared to ensure that no self-association would interfere with hetero-association. FTIR spectra of these solutions (Fig. S3) confirm that at $5 \mathrm{mM}$ in chloroform, monoureas are not associated. Moreover, the characteristic shift in the $\mathrm{N}-\mathrm{H}$ stretching vibration band going from $\mathbf{m M e}_{\mathbf{2}}-\mathbf{N H}$ to $\mathbf{m C l}_{2}-\mathbf{N H}$ (and from $\mathbf{m} \mathbf{M e}_{2}-\mathbf{N M e}$ to $\mathbf{m C l}_{2}-\mathbf{N M e}$ ) reveals the presence of intramolecular $\mathrm{HB}$ between $\mathrm{N}-\mathrm{H}_{\alpha}$ and chlorine atoms, as in the case of bis-ureas. The free N-H band intensity was also monitored while a $\mathrm{HB}$ acceptor was added. Figs. 4 and $\mathrm{S} 4$ clearly show that $\mathbf{m C l}_{\mathbf{2}} \mathbf{-} \mathbf{N H}$ is a better $\mathrm{HB}$ acceptor than $\mathbf{m M e}_{2}-\mathbf{N H}$. This experiment rules out the enhancement of $\pi$-stacking interactions as the main factor.

Moreover, Figs. 4 and S4 also show that $\mathbf{m M e}_{2}-\mathbf{N M e}$ and $\mathbf{m C l}_{\mathbf{2}}$-NMe are HB donors of similar magnitude. Therefore, the increase of intermolecular association by chlorine substitution is only effective if $\mathrm{N}-\mathrm{H}_{\beta}$ is present on the urea. We suggest that this is due to a conformational effect: the repulsion between the oxygen and chlorine atoms favourably orientates the N-H groups for hydrogen bonding. However, in the case of $\mathrm{N}-\mathrm{H}_{\alpha}$, the intramolecular $\mathrm{HB}$ annihilates this effect, which explains why the chlorine substitution is favourable only in the presence of $\mathrm{N}-\mathrm{H}_{\beta}$.

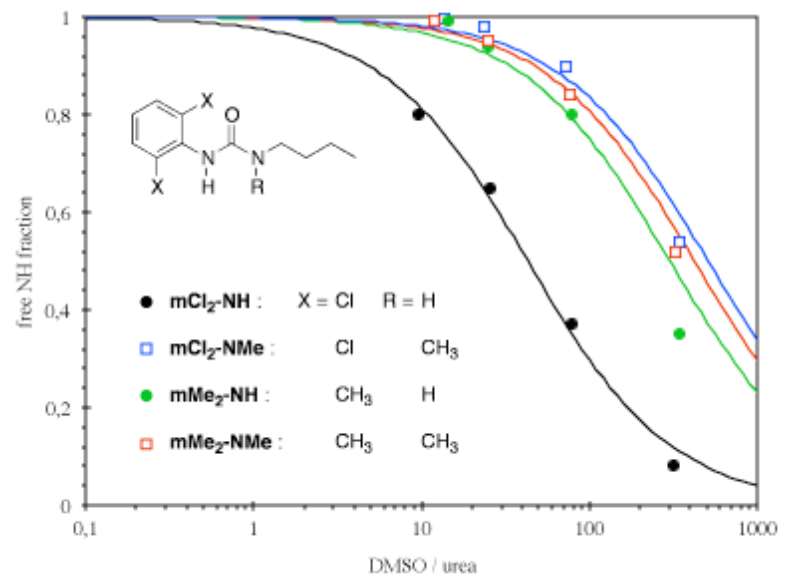

Fig. 4 Free N-H fraction determined by FTIR for mixtures of mono-ureas $\left(510^{-3} \mathrm{~mol} / \mathrm{L}\right)$ and DMSO in chloroform $\left(20^{\circ} \mathrm{C}\right)$. The curves are fits to a $1: 1$ association model.

In conclusion, we have shown by FTIR and $a b$ initio calculations that an intramolecular $\mathrm{HB}$ is formed when phenylureas are functionalized by chlorine or bromine atoms in ortho positions. Remarkably, the involvement of the aromatic N-H group in an intramolecular HB does not weaken the intermolecular hydrogen bond capacity of the urea group. On the contrary, the association constant of aromatic bis-ureas (measured by ITC) is improved by one order of magnitude when chlorine atoms replace methyl groups or even more when they replace hydrogen atoms in the ortho positions to the urea unit. This effect was demonstrated both in the context of bis-ureas self-association and of mono-ureas hydrogen bonding to strong HB acceptors. We suggest that this halogen effect is due at least in part to conformational constraints resulting from the repulsion between the oxygen and halogen atoms that favourably orientates the N-H groups for hydrogen bonding.

I.G. acknowledges financial support from the Università La Sapienza, COST Action "Supramolecular Chemistry in Water" and Egide. M.L. thanks SERC (Swedish e-Science Research Center) for funding and SNIC for providing computer resources. We thank François Boué (LLB, Saclay) for assistance with SANS experiments.

\section{Notes and references}

${ }^{a}$ UPMC Univ Paris 06, UMR 7610, Chimie des Polymères, F-75005

Paris, France. E-mail: laurent.bouteiller@upmc.fr

${ }^{b}$ CNRS, UMR 7610, Chimie des Polymères, F-75005 Paris, France

${ }^{c}$ Dipartimento di Chimica and IMC-CNR, Università La Sapienza, 00185

Roma, Italy

${ }^{d}$ Department of Physics, Chemistry and Biology (IFM), Linköping

University, SE-58183 Linköping, Sweden

$\dagger$ Electronic Supplementary Information (ESI) available: Additional data and experimental procedures. See DOI: 10.1039/b000000x/

\$ The vertical shift between the curves results from the significant differences in specific contrast among the bis-ureas (see Table S3).

1 M. M. Safont-Sempere, G. Fernández and F. Würthner, Chem. Rev. 2011, 111, 5784.

2 S. J. Brooks, P. R. Edwards, P. A. Gale and M. E. Light, New J. Chem. 2006, 30, 65.

3 N. Volz and J. Clayden, Angew. Chem. Int. Ed. 2011, 50, 12148.

4 J. J. Mousseau, L. Xing, N. Tang and L. A. Cuccia, Chem. Eur. J. 2009, 15, 10030.

5 J. Yang, M. B. Dewal, D. Sobransingh, M. D. Smith, Y. Xu and L. S. Shimizu, J. Org. Chem. 2009, 74, 102.

6 N. Mohmeyer and H.-W. Schmidt, Chem. Eur. J. 2007, 13, 4499.

7 K. Kishikawa, S. Nakahara, Y. Nishikawa, S. Kohmoto and M. Yamamoto, J. Am. Chem. Soc. 2005, 127, 2565.

8 V. Simic, L. Bouteiller and M. Jalabert, J. Am. Chem. Soc. 2003, 125, 13148.

9 S. Das, I. Yilgor, E. Yilgor and G. L. Wilkes, Polymer 2008, 49, 174.

10 M. Alajarin, A. Pastor, R.-A. Orenes, J. W. Steed and R. Arakawa, Chem. Eur. J. 2004, 10, 1383.

11 F. Vonau, D. Aubel, L. Bouteiller, G. Reiter and L. Simon, Phys. Rev. Lett. 2007, 99, 086103.

12 M. C. Etter, Z. Urbanczyk-Lipkowska, M. Zia-Ebrahimi and T. W. Panunto, J. Am. Chem. Soc. 1990, 112, 8415.

13 Y. Mido and C. Furusawa, J. Mol. Struct. 1982, 82, 23.

14 A. Abad, C. Agullo, A. C. Cunat, C. Vilanova and M. C. Ramirez de Arellano, Cryst. Growth Des. 2006, 6, 46.

15 (a) R. Emery, N. A. Macleod, L. C. Snoek and J. P. Simons, Phys. Chem. Chem. Phys. 2004, 6, 2816; (b) V. S. Bryantsev, T. K. Firman and B. P. Hay, J. Phys. Chem. A 2005, 109, 832.

16 (a) W. Dannecker, J. Kopf and H. Rust, Cryst. Struct. Commun. 1979, 8, 429; (b) M. R. Ciajolo, F. Leli, T. Tancredi, P. A. Temussi and A. Tuzi, Acta Cryst. 1982, B38, 2928; (c) S. George and A. Nangia, Acta Cryst. 2003, E59, 901; (d) R. A. Koevoets, R. M. Versteegen, H. Kooijman, A. L. Spek, R. P. Sijbesma and E. W. Meijer, J. Am. Chem. Soc. 2005, 127, 2999.

17 L. Bouteiller, O. Colombani, F. Lortie and P. Terech, J. Am. Chem. Soc. 2005, 127, 8893.

18 M. Bellot and L. Bouteiller, Langmuir 2008, 24, 14176.

19 A. Arnaud and L. Bouteiller, Langmuir 2004, 20, 6858. 